\title{
WHY DO WE STEP ON THE SAME RAKE? THE OCCURRENCE OF RECURRING ERRORS IN THE LEARNING PROCESS
}

\begin{abstract}
N.V. ANDRIYANOVA ${ }^{\mathrm{a}}$, V.M. ALLAKHVERDOV ${ }^{\mathrm{a}}$
${ }^{a}$ Saint Petersburg State University, 7/9 Universitetskaya emb., Saint Petersburg, 199034, Russian Federation

Abstract

The present study investigated the occurrence of recurring errors in the learning process. Our goal was to determine the reasons for recurring errors. In considering these reasons we were trying to find the characteristic features of incorrect responses at the beginning of a learning process in order to predict the occurrence of recurring errors in the learning process. Response times and confidence measures were used as the predictors of error repetition. The results of two experiments have shown that response times and confidence levels for the recurring and singular errors at the beginning of learning are different. Response times were shorter for recurring errors than for singular errors at the beginning of a learning process. This information can be used to predict the repetition of such errors further along during learning. In addition, in both experiments the correct responses were slower for stimuli that would cause recurring errors in the future. This allowed us to predict the repetition of such errors. Participants' confidence estimates also varied with different types of erroneous responses and allowed the repetition of errors during the learning process to be predicted. Thus, our results allow the prediction of error repetition and also can be used to make suggestions about the phenomenon of recurring errors and the causes of their occurrence.
\end{abstract}

Keywords: recurring errors, learning, contradictions, response time, predicting, confidence.

\section{Introduction}

There is a well-known proverb in Russia: "To step on the same rake”. It means to repeat an error. Many researchers find recurring errors in their studies. It is obvious that the repetition of errors in the same situation may be caused by the same factors that led to the errors. There are many studies about systematic errors resulting from the initially erroneous choice of a goal (e.g., Reason, 1990; Norman, 2002). Some authors suggest that the error repetition effect can be attributed to the implicit learning of an erroneous state. Humphreys, Menzies and Lake (2010) and D'Angelo and Humphreys (2015) explain recurring errors as the implicit learning of an incorrect mapping from lemma to phonology for a particular word. D'Angelo and Humphreys (2015) investigated whether the tip-ofthe-tongue (TOT) effect tends to reoccur on particular words. The authors have found

The research was supported by the RFBR according to the research project № 20-013-00778 A. 
that participants tend to experience TOT during the test despite the fact that they were given the correct answer directly before. Humphreys, Menzies and Lake (2010) investigated recurring errors to study whether there is a tendency for speech errors to reoccur in specific words. In their experiments (using the SLIP procedure) they showed that when speakers made a phonological speech error in the study phase of an experiment, they were more than four times as likely to make an error on that same item several minutes later in the test.

Many studies are focused on the phenomenon of errorless learning. Special attention is paid to implicit errorless learning because it is more difficult to eliminate errors during this type of learning. There are many studies on the material of memory problems. It was shown that amnesic people have good implicit but bad explicit learning; such participants learn new information better in the case of errorless learning (e.g., Baddeley \& Wilson, 1994). A number of works are devoted to this phenomenon in motor skill learning. Poolton, Masters and Maxwell (2005) showed in their experiments that in the case of hypothesis testing strategies participants were less successful in motor skill tasks than after a brief period of errorless learning. Thus, some researchers conclude that errorless learning is more effectively since it allows avoiding the repetition and consolidation of errors.

In Allakhverdov's works $(1993,2008)$ the fact is emphasized that the repetition of errors may occur even if these errors are unconscious. The repetition of such errors can be caused by the very fact of making an error. The researcher suggests that once a decision is made, it influences the processing that follows resulting in stable awareness (a positive choice aftereffect) or unawareness of items (a negative choice aftereffect). He shows that once-missed, undetected or detected wrong items tend to be more often detected as wrong than new stimuli in the trials that follow. For example, unawareness of one meaning of an ambiguous image slows down the solution of tasks related to this meaning. This explanation presumes the repetition of unawareness, thus it is possible to repeat not only the same errors but also different ones. In an experiment when participants had to shoot at a moving target with a rocket, it was shown that most tend to repeat their responses with a high level of accuracy (higher than the accuracy of correct actions) and these errors appeared to be more frequent than if they occurred by chance. In addition, a high correlation was found between the dynamics of learning and the quantity of recurring errors (Allakhverdov, 2008).

Similar results were found in later studies. E.g., VanRullen and Koch (2003) asked participants in their experiments to memorize photos of city views that contained various objects. It was shown that when participants cannot recall a particular object, such as a bus, they tend to make more errors in subsequent tasks and perform a task more slowly if it involves the missed object. The authors suggest that the remaining objects are actively inhibited because of limited resources for information processing. It produces an interference between the selected and inhibited information, therefore in the tasks participants should first overcome the inhibition of remaining objects before they can react to these objects. Thus, they identify such objects more slowly and make more errors. Hajcak and Simons (2008) described recurring errors as making an error in the subsequent trial if the previous answer was erroneous too. In experiments employing the Stroop task, authors demonstrated that recurring errors reduce the response time in comparison to the time of transition to a correct answer and the response time for singular errors. The authors suggest that recurring errors are a new type of errors that are caused by a failure of compensatory processes governing speed and accuracy of performing tasks. 
Analysis of the empirical data demonstrated that people can unconsciously distinguish their correct and erroneous answers even if they do not have explicit knowledge about the correctness of their answers. It was shown that people tend to make correct judgments more quickly and more confidently in similar tasks than false judgments even if they cannot identify the efficiency of their actions (e.g., Allakhverdov, 1993, 2008; Petrusic \& Baranski, 1998). In other studies it was shown that people tend to slow down their answers after errors even without feedback about the errors (e.g., Houtman, Núñez Castellar, \& Notebaert, 2012; Crump \& Logan, 2013). Unconscious error detection was suggested in psychophysiological studies. Bechtereva et al. (2005) described the mechanism of "error detection" that provides a stable functional state of the brain in comparison to the actual state with the conditional model of memory. Initial error awareness studies found that the error-related negativity activated equally for aware and unaware errors (e.g., Endrass, Reuter, \& Kathmann, 2007).

One of the reasons for repetition and increase in errors can be the tendency to resolve contradictions between erroneous behavior and unconscious knowledge of the correct answer. In this case the person unconsciously accepts the previous error as a correct answer and therefore tends to repeat it in order to avoid the contradiction. Karpinskaia and Lyakhovetskii (2013) investigated the influence of different illusions on sensorimotor evaluation. It is a well-known fact from psychophysics that the higher the value of the stimulus, the higher the sensitivity. The authors found that an illusory change in the size of stimuli (using visual illusions and the Charpentier size-weight illusion) leads to a change in sensitivity. Perhaps, after the illusory error, participants unconsciously decide that they have not committed an error (reducing cognitive dissonance) and act as if the size of the stimulus had really been changed.

The present work is aimed at verifying this assumption. We suggest that a person, when committing an error, has two ways of avoiding the contradiction: to repeat this error or to correct this error. According to the described explanation of recurring errors, it can be suggested that there will be a difference in the response times and the confidence levels for recurring and singular errors at the beginning of a learning process. Such differences will be the basis for the prediction of error repetitions during learning that will enable the correction of such errors in the learning process and prevent them from being consolidated.

Different authors suggest different definitions for recurring errors. For example, Vitkovitch and Rutter (2000) determine recurring errors as the values of previous erroneous responses that more frequently occur later than would be expected through a random chance. Humphreys, Menzies and Lake (2010) and D'Angelo and Humphreys (2015) describe a recurring error as an error on the same task at study phase and at test, but it is not necessarily an identical erroneous answer. Based on these definitions, but considering the specificity of our material, we also incorporate different types of recurring errors. These types are described in the Methods section.

\section{Methods}

Two experiments were conducted involving an identification task. We used tasks with multiple presentations of similar stimuli for a short time. Such a design allows time for a sufficient number of errors to occur. In the experiments we used a similar procedure but different stimuli. 
Participants: 120 students (86 females, $18-28$ years old) of Saint Petersburg State University voluntarily participated in the experiments (60 participants in each experiment). They were not paid for their participation. All reported normal or corrected-tonormal visual acuity.

Apparatus and stimuli. In the first experiment images of clock faces with different arrows representing clock hands were used as stimuli. In the second experiment images of $10 \times 10$ chessboards with one chess piece were used as stimuli. All stimuli were presented on the 19-inch computer screen. PsychoPy software was used for presenting the stimuli and recording responses (Peirce, 2007).

Procedure and design. In the first experiment, participants were shown images of clock faces indicating a particular time for 200 milliseconds (ms), one after another. After each stimulus an input box appeared on the screen where the participant was required to enter the time indicated on the clock face (e.g., 3.20). Participants were instructed to respond as quickly as they could. A total of 120 trials were used in the experiment to be grouped into 10 series. In each series 12 stimuli were presented in a different order.

In the second experiment participants were presented with images of $10 \times 10$ chessboards with one chess piece for $200 \mathrm{~ms}$, one after another. Immediately afterwards an image of chessboard with labels for all positions was presented as a hint. Participants were to click the enter button when they were ready to give an answer. Following the hint after each stimulus, an input box appeared on the screen for the participants to enter the position of the previously presented chess piece (e.g., e5). Participants were instructed to respond as quickly as they could. We use the images of $10 \times 10$ chessboards instead of $8 \times 8$ chessboards in order to make stimuli less typical for people who are familiar with chess notation. As well as in the first experiment, there was a total of 120 trials to be grouped into 10 series.

During the tasks the progression responses and response times for stimuli were recorded. Comparisons were made between (i) response times of correct responses, (ii) latencies of singular errors that did not repeat, (iii) latencies of recurring errors at the beginning of the learning process (the first incorrect response to a particular stimulus) and (iv) latencies of recurring errors during the learning process (the second and following incorrect responses to the same stimulus). We also analyzed response times of correct responses before errors on the next series of the same stimulus (e.g., the correct response 3.20 in the second series and 3.25 instead of 3.20 in the third series). The response times of correct responses were compared before singular errors that did not repeat and before first incorrect responses that repeated in the course.

In the first experiment an input box appeared immediately after each stimulus; the interval between the end of a stimulus presentation and the end of entering a response was used as the response time. In the second experiment participants decided on their responses during the presentation of the hint. In this experiment the interval between the end of a stimulus presentation and the end of a hint presentation was used as the response time. Therefore, the response times in the second experiment were shorter on average than in the first experiment.

We consider the recurring error to be an incorrect response to the same stimulus in the next series (e.g., 3.15 instead of 3.20 in the second series and 3.25 instead of 3.20 in the third series). In addition, we consider the recurring errors of replacement separately identical incorrect responses to the same stimulus in the next series (e.g., 3.15 instead of 3.20 in the third series and 3.15 instead of 3.20 in the fourth series). 
Also half of the participants in each experiment were required to estimate confidence in their responses after each trial. A one to five point scale was used (with "one" meaning the least confident response and "five" meaning the most confidence in a given response). The other half of the participants did not estimate confidence in order to take into account the possible impact of the confidence estimation task. Thus, in each experiment participants were randomly assigned to the group with the estimation of confidence $(\mathrm{N}=30)$ or to the group without the estimation of confidence $(\mathrm{N}=30)$.

Student's $t$-test for paired comparisons and analysis of variance (ANOVA) with repeated measures were used for statistical analysis. The post hoc Tukey was applied in the case of significant differences.

\section{Results}

The probability of recurring errors and the probability of singular errors were compared. In the first experiment the probability of singular errors $(20 \%)$ was significantly lower than the probability of recurring errors $(37 \%), t(21)=4.560 ; p<.01$. In the second experiment there are also statistically significant differences between the possibilities of singular $(25 \%)$ and recurring errors $(33 \%), t(26)=3.028 ; \mathrm{p}<.01$.

\section{Response Times}

Mean response times (RTs) for different types of responses are presented in Table 1. There were no significant differences in the number of errors between groups of participants with and without confidence estimation. Therefore we analyzed the RTs for all 60 participants in common in each experiment.

In the first experiment for the recurring errors of replacement, there were statistically significant differences in the RTs $(\mathrm{F}(3,147)=13.7, p<.001)$. For the commission of singular errors, response times were significantly longer than for correct responses (post-hoc Tukey test $p<.001)$ and for recurring errors during the learning process $(p<0.001)$. There were no significant differences in the RTs for correct responses or recurring errors during the learning process $(p=.97)$. The RTs were significantly shorter compared to singular errors $(p=.002)$ for recurring errors committed at the beginning of learning, and there were no significant differences in RTs for recurring errors during learning $(p=.51)$ (Table 1).

In the second experiment for recurring errors of replacement there were also statistically significant differences in the $\mathrm{RTs}(\mathrm{F}(3,156)=7.128, p<.001)$. For singular errors

Table 1

Mean Response Times (ms) of Responses (Standard Deviations in Parentheses)

\begin{tabular}{|l|c|c|}
\hline \multicolumn{1}{|c|}{ Responses } & Experiment 1 & Experiment 2 \\
\hline Correct responses & $5301(1391)$ & $2360(863)$ \\
\hline Repeated incorrect responses & $5564(1629)$ & $2549(1191)$ \\
\hline First incorrect responses & $6092(1811)$ & $2694(998)$ \\
\hline Singular (not repeating) errors & $7078(1889)$ & $3146(1325)$ \\
\hline
\end{tabular}


RTs were significantly longer than for correct responses (post-hoc Tukey test $p<.001$ ) and for recurring errors during the learning process $(p=.002)$. For recurring errors at the beginning of the learning process RTs were significantly shorter compared to singular errors $(p=.03)$, and there were no significant differences in response times for recurring errors during learning ( $p=.91$ ) (Table 1). Thus, at the beginning of the learning process it is possible to predict particular stimuli that will lead to recurring errors of replacement during the learning process.

\section{Confidence}

Mean confidence ratings for different types of responses are presented in Table 2. In the first experiment the analysis of the confidence data showed statistically significant differences in the evaluation of correct and incorrect responses $(\mathrm{F}(3,87)=18.49, p<.001)$. Participants were more certain of their correct responses than they were of their incorrect responses (post-hoc Tukey test $p=.001$ ). Confidence levels of recurring errors of replacement at the beginning and during the learning process were reliably higher than for singular errors $(p=.002)$ (Table 2$)$.

In the second experiment the results of the confidence level data analysis correspond to those found in Experiment 1 (Table 2). The analysis of the confidence data showed statistically significant differences in the evaluation of correct and incorrect responses $(\mathrm{F}(3$, $84)=17.35, p<.001)$. Thus, when participants repeated errors they became more confident that they had responded correctly, but this confidence was not as high as for the correct responses (post-hoc Tukey test $p=.01$ ). Confidence levels of recurring errors of replacement at the beginning and during the learning process were reliably higher than for singular errors $(p=.01)$. The level of confidence of repeated incorrect responses allows the prediction of repeated errors during the learning process.

The responses that had the highest confidence values (4-5 points) were compared with those that had the lowest confidence values (1-3 points). The results of 28 participants who had both high and low values for all types of answers were used for this analysis. In the first experiment it was found that the RTs were significantly shorter for the confident responses, $t(27)=4.759 ; p<.01$. However, even for the less confident responses the RTs for correct responses $(\mathrm{M}=6227 \mathrm{~ms}, \mathrm{SD}=1682)$ and recurring errors $(\mathrm{M}=6134 \mathrm{~ms}$, $\mathrm{SD}=2254)$ were quicker than for singular errors $(\mathrm{M}=7746 \mathrm{~ms}, \mathrm{SD}=2038), t(27)=4.007$; $p<.01$. For the confident responses the RTs for correct responses $(\mathrm{M}=5202 \mathrm{~ms}$,

Table 2

\section{Mean Confidence Ratings of Responses from 1 to 5 Points (Standard Deviations in Parentheses)}

\begin{tabular}{|l|c|c|}
\hline \multicolumn{1}{|c|}{ Responses } & Experiment 1 & Experiment 2 \\
\hline Correct responses & $4.2(0.85)$ & $3.8(0.87)$ \\
\hline Repeated incorrect responses & $3.9(0.93)$ & $3.5(0.84)$ \\
\hline First incorrect responses & $3.8(0.84)$ & $3.4(0.81)$ \\
\hline Singular (not repeating) errors & $3.4(0.73)$ & $3.1(0.79)$ \\
\hline
\end{tabular}


$\mathrm{SD}=1682)$ and recurring errors $(\mathrm{M}=5389 \mathrm{~ms}, \mathrm{SD}=2254)$ were also quicker than for singular errors $(\mathrm{M}=7011 \mathrm{~ms}, \mathrm{SD}=2038), t(27)=5.729 ; p<.01$ (Figure 1$)$.

In the second experiment there were 22 participants who had both high and low values for all types of answers. It was found that the RTs were quicker for confident responses but only for correct responses and singular errors, $t(21)=2.212 ; p=.03$. However, even for non-confident responses it was found that participants produced correct responses $(\mathrm{M}=$ $2875 \mathrm{~ms}, \mathrm{SD}=943)$ and recurring errors $(\mathrm{M}=2931 \mathrm{~ms}, \mathrm{SD}=1339)$ more quickly than singular errors $(\mathrm{M}=3957 \mathrm{~ms}, \mathrm{SD}=1993), t(21)=3.443 ; p<.01$ (Figure 1). This suggests that participants can implicitly distinguish their correct and false responses even if they are not confident in their responses. For the confident responses the RTs for correct responses $(\mathrm{M}=2375 \mathrm{~ms}, \mathrm{SD}=791)$ also quicker than for singular errors $(\mathrm{M}=3066 \mathrm{~ms}$, $\mathrm{SD}=1276), t(21)=2.956 ; p<.01$. There were no significant differences in the RTs for singular and recurring errors, $t(21)=0.39 ; p=.88$.

\section{Response Times before Errors}

In addition to the comparison of RTs of recurring and singular errors, we compared the RTs of correct response before recurring and singular errors on the same stimuli. In the first experiment statistically significant differences were found in RTs for the correct responses before recurring errors and before singular errors on the same stimuli. RTs for correct responses before recurring errors on the same stimuli were significantly longer than for RTs before singular errors on the same stimuli, $t(55)=2.74 ; p<.01$ (Table 3 ).

In the second experiment the results of the analysis of response times for the correct responses before errors correspond to those found in Experiment 1. RTs for correct responses before recurring errors on the same stimuli were significantly longer than for RTs

Figure 1

Mean Response Time for Confident and Non-Confident Responses. The Error Bars Indicate Standard Errors of the Mean

Experiment 1

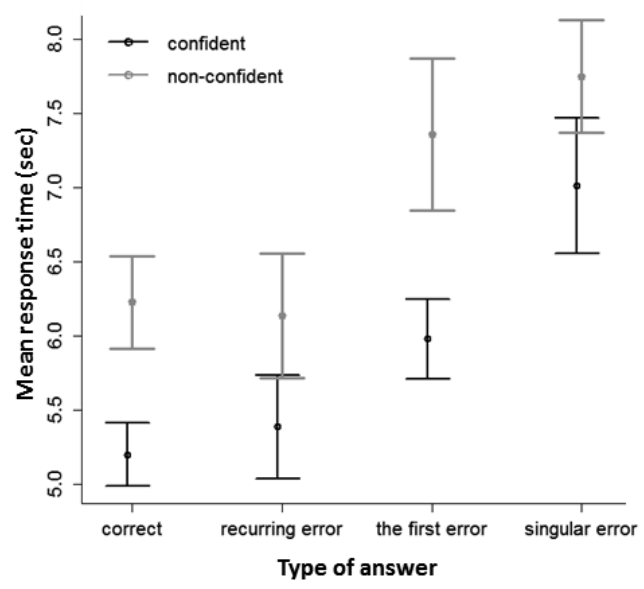

Experiment 2

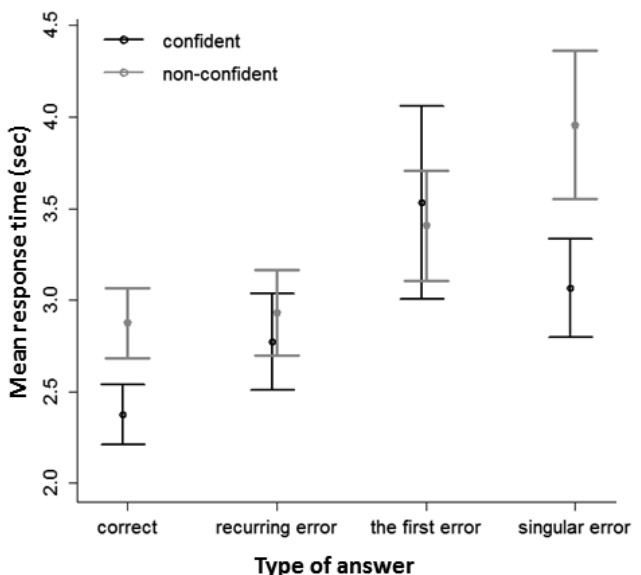


Mean Response Times (ms) of Correct Responses before the Errors on the Same Stimuli (Standard Deviations in Parentheses)

\begin{tabular}{|l|c|c|}
\hline \multicolumn{1}{|c|}{ Responses } & Experiment 1 & Experiment 2 \\
\hline Before singular error & $5743(1715)$ & $2420(937)$ \\
\hline Before recurring error & $6322(2162)$ & $2714(1328)$ \\
\hline
\end{tabular}

before singular errors on the same stimuli, $t(59)=3.082 ; p<.01$ (Table 3 ). Thus, in both experiments we can observe an increase in response times before recurring errors on the same stimuli, and this allows us to predict the repetition of errors in these stimuli during learning.

The results show that participants committed recurring errors in the identification of similar stimuli. In both experiments the response times for the commission of recurring errors of replacement at the beginning of the learning process allowed us to predict the emergence of errors and their stability during the learning process. Also, in both experiments the level of confidence in repeated incorrect responses allows us to predict the repetition of errors during the learning process. Finally, it is also possible to predict the repetition of these errors during the learning process by measuring the latencies of correct responses before recurring errors at the beginning of learning.

\section{Discussion}

Analysis of the results has shown that response times and confidence levels for the recurring and singular errors at the beginning of learning are different. Participants are inclined to make recurring errors that are almost as fast and as confident as their correct responses. Such results suggest that people do not perceive repeated incorrect responses as incorrect, and therefore make recurring errors more quickly and more confidently than singular errors. Moreover, it was found that confident responses tend to be given more quickly than non-confident responses. Similar results have been found in different experiments, e.g., by Kelley and Lindsay (1993) in mnemonic tasks; by Wright and Ayton (1988) in general awareness tasks; by Shaw, McClure and Wilkens (2001) in face detection tasks. However, even for participants' non-confident responses, the response times for correct responses and recurring errors were shorter than for singular errors. Even though participants do not have explicit confidence, participants tend to distinguish their correct and false responses using the response time as a detector of confidence.

The latencies of the correct responses before recurring and singular errors are also different. The deceleration of correct responses before recurring errors might mean that a participant is not confident in the correctness of the response and furthermore can change the response to an incorrect one. In this way the detection of errors can appear before giving a response, indicating the possibility of error prediction. Similar results were demonstrated by Rabbitt (1978) who showed that skilled typists tend to weaken the finger force before typing an erroneous word. So, the response time can also be the predictor of error.

Thus, recurring errors differ from singular errors. Some of the features of recurring errors described above appear at the beginning of learning. Even at the beginning of the 
experiment participants tended to give repeated erroneous responses more quickly and with greater confidence and to slow down correct responses before making recurring errors. Using the features of recurring errors revealed at the beginning of learning, it is possible to predict the repetition of incorrect responses to the same stimuli during the learning process.

It is difficult to explain the results of our experiments by the idea of limited resources. According to VanRullen and Koch (2003), we can suggest that in our experiments misnamed stimuli are inhibited, therefore participants tend to make more errors on them. However, the idea of limited resources does not explain the result that repeated erroneous responses are quicker and more confident than responses with singular errors. It also does not explain why people tend to repeat identical errors (recurring errors of replacement in our experiments). This approach does not suggest unconscious knowledge of a correct answer, thus does not explain our results about the difference between singular and recurring errors.

It seems that the idea of resolving the contradiction explains the majority of our results. If people tend to repeat their errors in order to avoid contradictions between their response and the correct one, it is clear why they give these responses almost as fast and as confidently as their correct responses. This approach is not based on the idea of limited resources, but it suggests that the very stimulus is ambiguous. At the same time we objectively perceive both the correct response and some erroneous decisions that we can take as correct ones, particularly, because these decisions were chosen earlier (Filippova, Kostina, \& Mezentseva, 2018). Thus, this approach also explains why people tend to repeat identical errors (recurring errors of replacement) as the repetition of the same error allows them to commute the contradiction. However, this approach does not explain the result about the deceleration of correct responses before recurring errors.

Assumedly error repetition could be a consequence of some other, possibly unconscious, decisions. For example, when solving problems of the same type, people can determine that they are not able to cope with all problems accurately. Thus they determine the probability of correctness of their actions for the task, although they are not always aware of it. When they are allowed to make a certain amount of errors they estimate their actions as effective. It is easier to control the effectiveness when you make errors to the same stimuli. Thus, people can implicitly select specific problems in which they will make errors.

The idea that people can unconsciously control the effectiveness of their own task solution could explain the deceleration of correct responses before recurring errors. At the beginning of learning people estimate the difficulty of tasks and choose the stimuli where they will make errors. The deceleration can mean the choice between correct and erroneous response. Their readiness to commit errors results in the deceleration of the correct response. This is a marker that the response to this stimulus could change to an erroneous response at the next trial and then reoccur in subsequent trials. However, this approach does not imply that recurring errors should necessarily be identical. It is only important that errors should be on the same stimuli. Thus, a quicker and more confident repetition of the same erroneous responses can result from the tendency to commute the contradictions. The deceleration of the correct response, which will change to the erroneous on the next trial, could be due to the choice between the correct and erroneous responses. This explanation requires further verification. 
In conclusion, in the current work we suggest ways of predicting recurring errors that undoubtedly could be of practical importance. For example, it was shown that sportsmen often repeat their errors in stressful conditions and with a high cognitive load, especially when they know about their typical errors (e.g., Beilock, Afremow, Rabe, \& Carr, 2001; Hanin, Korjus, Jouste, \& Baxter, 2002). In our further work we are planning to study the ways of coping with recurring errors in different practical fields. At the same time our results can be used to make suggestions about the phenomenon of recurring errors and the causes of their occurrence.

\section{References}

Allakhverdov, V. M. (1993). Opyt teoreticheskoi psikhologii (v zhanre nauchnoi revoliutsii) [The experience of theoretical psychology]. Saint Petersburg: Pechatnyi dvor. (in Russian)

Allakhverdov, V. M. (2008). Awareness as a result of choice. Psychology in Russia: State of the Art, 1, 136-152. doi:10.11621/pir.2008.0009

Baddeley, A. D., \& Wilson, B. A. (1994). When implicit learning fails: Amnesia and the problem of error elimination. Neuropsychologia, 32(1), 53-68. doi:10.1016/0028-3932(94)90068-X

Bechtereva, N. P., Shemyakina, N. V., Starchenko, M. G., Danko, S. G., \& Medvedev, S. V. (2005). Error detection mechanisms of the brain: Background and prospects. International Journal of Psychophysiology, 58, 227-234. doi:10.1016/j.ijpsycho.2005.06.005

Beilock, S. L., Afremow, J. A., Rabe, A. L., \& Carr, T. H. (2001). “Don’t miss!” The debilitating effects of suppressive imagery on golf putting performance. Journal of Sport and Exercise Psychology, 23, 200-221. doi:10.1123/jsep.23.3.200

Crump, M. J. C., \& Logan, G. D. (2013). Prevention and correction in post-error performance: An ounce of prevention, a pound of cure. Journal of Experimental Psychology: General, 142(3), 692709. doi:10.1037/a0030014

D’Angelo, M. C., \& Humphreys, K. R. (2015). Tip-of-the-tongue states reoccur because of implicit learning, but resolving them helps. Cognition, 142, 166-190. doi:10.1016/j.cognition.2015.05.019

Endrass, T., Reuter, B., \& Kathmann, N. (2007). ERP correlates of conscious error recognition: aware and unaware errors in an antisaccade task. European Journal of Neuroscience, 26(6), 1714-1720, doi:10.1111/j.1460-9568.2007.05785.x

Filippova, M., Kostina, D., \& Mezentseva, M. (2018). Recognition dynamics for unnoticed meanings of ambiguous figures. Psikhologicheskii Zhurnal, 39(3), 44-56. doi:10.7868/S0205959218030042

Hanin, Y., Korjus, T., Jouste, P., \& Baxter, P. (2002). Rapid technique correction using old way/new way: Two case studies with Olympic athletes. The Sport Psychologist, 16(1), 79-99. doi:10.1123/tsp.16.1.79

Hajcak, G., \& Simons, R. F. (2008). Oops!.. I did it again: an ERP and behavioral study of double errors. Brain and Cognition, 68, 15-21. doi:10.1016/j.bandc.2008.02.118

Houtman, F., Núñez Castellar, E., \& Notebaert, W. (2012). Orienting to errors with and without immediate feedback. Journal of Cognitive Psychology, 24(3), 278-285. doi:10.1080/20445911.2011.617301

Humphreys, K. R., Menzies, H., \& Lake, J. K. (2010). Repeated speech errors: Evidence for learning. Cognition, 117, 151-165. doi:10.1016/j.cognition.2010.08.006 
Karpinskaia, V., \& Lyakhovetskii, V. (2013). The sensorimotor evaluation of perceptual illusions. Procedia - Social and Behavioral Sciences, 86, 323-327. doi:10.1016/j.sbspro.2013.08.572

Kelley, C. M., \& Lindsay, S. D. (1993). Remembering mistaken for knowing: Ease of retrieval as a basis for confidence in answers to general knowledge questions. Journal of Memory and Language, 32(1), 1-24. doi:10.1006/jmla.1993.1001

Norman D. (2002). The design of everyday things. New York: Basic Books.

Peirce, J. W. (2007). PsychoPy - Psychophysics software in Python. Journal of Neuroscience Methods, 162(1-2), 8-13. doi:10.1016/j.jneumeth.2006.11.017

Petrusuc, W. M., \& Baranski, J. V. (1998). Probing the locus of confidence judgments: Experiments on the time to determine confidence. Journal of Experimental Psychology: Human Perception and Performance, 24(3), 929-945. doi:10.1037//0096-1523.24.3.929

Poolton, J. M., Masters, R. S. W., \& Maxwell, J. P. (2005). The relationship between initial errorless learning conditions and subsequent performance. Human Movement Science, 24(3), 362-378. doi:10.1016/j.humov.2005.06.006

Rabbitt, P. (1978). Detection of errors by skilled typists. Ergonomics, 21(11), 945-958. doi:10.1080/00140137808931800

Reason, J. T. (1990). Human error. New York: Cambridge University Press.

Shaw, J. S., McClure, K. A., \& Wilkens, C. E. (2001). Recognition instructions and recognition practice can alter the confidence - Response time relationship. Journal of Applied Psychology, 86, 93-103. doi:10.1037/0021-9010.86.1.93

VanRullen, R., \& Koch, C. (2003). Competition and selection during visual processing of natural scenes and objects. Journal of Vision, 3(1), 75-85. doi:10.1167/3.1.8

Vitkovitch, M., \& Rutter, C. (2000). The effects of response stimuli interval on error priming in sequential object naming. Visual Cognition, 7(5), 645-670. doi:10.1080/135062800407239

Wright, G., \& Ayton, P. (1988). Decision time, subjective probability and task difficulty. Memory and Cognition, 16, 176-185. doi:10.3758/BF03213487

Natalia V. Andriyanova - Senior Lecturer, Saint Petersburg State University, PhD in Psychology.

Research Area: cognitive psychology, experimental psychology, learning, repeated errors, sport psychology.

E-mail: andriyanova89@mail.ru

Victor M. Allakhverdov - Professor, Saint Petersburg State University, Doctor of Psychology. Research Area: cognitive psychology, experimental psychology, methodology and history of psychology.

E-mail: vimiall@gmail.com 


\title{
Почему мы наступаем на одни и те же грабли? Возникновение повторяющихся ошибок в процессе научения
}

\author{
Н.В. Андриянова ${ }^{a}$, В.М. Аллахвердов ${ }^{a}$ \\ ${ }^{a}$ Санкт-Петербургский государственный университет, 199034, Россия, Санкт-Петербург, \\ Университетская наб., д. 7/9
}

\section{Резюме}

Данное исследование направлено на изучение возникновения повторяющихся ошибок в процессе научения. Нашей целью является определить причины повторяющихся ошибок, определив которые мы пытаемся выделить черты ошибочных ответов уже в начале процесса научения. Данные черты позволят прогнозировать повторение ошибок при продолжении процесса научения. В качестве предикторов повторения ошибок мы используем время ответа и степень уверенности в ответе. Результаты двух экспериментов показали, что время ответов и степень уверенности различаются для одиночных и повторяющихся ошибочных ответов. Время повторяющегося ошибочного ответа в начале процесса научения меньше, чем время одиночного ошибочного ответа. Такой результат позволяет прогнозировать повторение ошибок при продолжении процесса научения. Кроме того, в обоих экспериментах было обнаружено замедление правильных ответов на стимулах, на которых в дальнейшем возникают повторяющиеся ошибки. Более медленные правильные ответы перед повторяющимися ошибками позволяют прогнозировать повторение ошибок. Оценки степени уверенности испытуемых различаются для разных типов ошибочных ответов, повторяющиеся ошибочные ответы оцениваются как более уверенные, чем одиночные. Такие различия также позволяют прогнозировать повторение ошибок при продолжении процесса научения. Таким образом, полученные результаты позволяют прогнозировать повторение ошибок, а также расширяют понимание феномена повторяющихся ошибок и причин их возникновения.

Ключевые слова: повторяющиеся ошибки, научение, противоречия, время ответа, прогнозирование, уверенность.

Андриянова Наталья Владимировна - старший преподаватель, кафедра общей психологии, Санкт-Петербургский государственный университет, кандидат психологических наук. Сфера научных интересов: когнитивная психология, экспериментальная психология, научение, повторяющиеся ошибки, психология спорта.

Контакты: andriyanova89@mail.ru

Аллахвердов Виктор Михайлович - профессор, кафедра общей психологии, СанктПетербургский государственный университет, доктор психологических наук, профессор. Сфера интересов: когнитивная психология, экспериментальная психология, методология и история психологии.

Контакты: vimiall@gmail.com 